\title{
Uma análise dos aspectos distributivos da aposentadoria por tempo de contribuição do INSS com o emprego de matemática atuarial
}

\author{
Luís Eduardo Afonso ${ }^{1}$, Daniela de Almeida Lima ${ }^{1}$
}

\author{
${ }^{1}$ Faculdade de Economia, Administração e Contabilidade da Universidade de São Paulo. \\ Correspondência: E-mail: lafonso@usp.br \\ Faculdade de Economia, Administração e Contabilidade (FEA-USP) \\ Av.Prof.Luciano Gualberto, 908 - CEP: 05508-010 - São Paulo - SP - Brasil
}

Resumo O objetivo do artigo é o cálculo de parâmetros usualmente adotados na literatura sobre previdência social, como as taxas de reposição previdenciária, alíquotas de contribuição atuarialmente justa e valores presentes de contribuições e de benefícios, para o caso brasileiro. Os cálculos são feitos para a Aposentadoria por Tempo de Contribuição (ATC) do Regime Geral de Previdência Social (RGPS) do INSS. Com tal finalidade, é construído um modelo atuarial simples para um regime previdenciário de repartição. O diferencial deste artigo em relação a trabalhos anteriores que empregavam modelos deterministas é a modelagem dos fluxos previdenciários, feita por meio de técnicas de matemática atuarial, incorporando o risco biométrico. Os cálculos são feitos para diferentes combinações de gênero, idade de início da vida laboral, renda e taxa de desconto. Os resultados mostram que as alíquotas de contribuição do RGPS, (28\% a 31\%), são mais do que suficientes para financiar a ATC, principalmente para os homens de renda mais elevada e que iniciaram sua vida ativa mais tarde. Os resultados fornecem evidências que as taxas de reposição (próximas a $0,5)$ são similares às verificadas em países desenvolvidos. Os resultados permitem três conclusões principais. A primeira é que o sistema previdenciário tem impactos distributivos intrageracionais, particularmente no tocante a gênero. A segunda é que parece ser razoável pensar em equiparação nas regras da ATC para homens e mulheres. Em terceiro lugar deve-se atentar para a influência do Fator Previdenciário sobre as questões distributivas.

Palavras-chave: previdência social, alíquota de contribuição, aposentadoria por tempo de contribuição, matemática atuarial, Fator Previdenciário. 
Abstract

The aim of the paper is calculating parameters usually adopted in the literature on social security, such as pension replacement rates, actuarially fair contribution rates and present values of contributions and benefits, for Brazil. The calculations are performed for the Length of Contribution Pension (ATC) of the RGPS of INSS. To reach that goal, an actuarial model is constructed for a pay-as-you-go pension system. The differential of this article in relation to previous work, that employed deterministic models, is the modeling of flows pension, made by techniques of actuarial mathematics, incorporating biometric risk. Calculations are made for different combinations of gender, age at onset of labor income and discount rate. The results show that the rates of contribution of RGPS (28\% to $31 \%$ ) are more than enough for the ATC benefit, especially for men with higher income and who started his working life later. The results also provide evidence that replacement rates are similar to those experienced in developed countries. The results allow three main conclusions. The first is that the Brazilian pension system has intragenerational distributive impacts, particularly with regard to gender. The second is that it seems reasonable to think of equalization for the rules of ATC for men and women. Thirdly, one must pay attention to the influence of Fator Previdenciário on distributional issues.

Keywords: social security, contribution rate, length of contribution pension, actuarial mathematics, Fator Previdenciário.

Resumen El objetivo de este trabajo es el cálculo de los parámetros comúnmente utilizados en la literatura sobre la seguridad social, como las tasas de reemplazo de pensiones, las tasas de contribución, y el valor actual actuarial justo de contribuciones y beneficios para el caso brasileño. Los cálculos se realizan para la jubilación por duración de Contribución (ATC) de lo Regime Geral de Previdência Social (RGPS) del INSS. Con este fin, un modelo actuarial simples se construye del plan de pensiones. El diferencial de este artículo en relación con trabajos previos que emplean los modelos deterministas es la modelización de los flujos de pensiones, obtenidos mediante técnicas de matemática actuarial, la incorporación de los riesgos biométricos. Los cálculos se realizan para diferentes combinaciones de género, edad de inicio de trabajo, los ingresos y tasa de descuento. Los resultados muestran que las tasas de contribución del RGPS $(28 \%$ a $31 \%$ ) son más que suficientes para financiar la ATC, especialmente para los hombres con mayores ingresos y que comenzó su vida laboral más tarde. Los resultados proporcionan evidencia de que las tasas de sustitución (cerca de 0,5) son similares a las observadas en países desarrollados. Los resultados permiten tres conclusiones principales. La primera es que el sistema brasileño de pensiones tiene intrageneracional efectos distributivos, en particular con respecto al género. La segunda es que parece razonable pensar que coinciden con las reglas de la ATC para hombres y mujeres. En tercer lugar deben estar atentos a la influencia del Fator Previdenciario en los problemas de distribución.

Palabras-clave: seguridad social, la tasa de cotización, período de cotización para la jubilación, la matemática actuarial, el Fator Previdenciário. 


\section{Introdução}

Muito se tem discutido a respeito da necessidade de se equilibrar os fluxos de contribuições e de benefícios da previdência social no Brasil, seja no Regime Geral de Previdência Social (RGPS) do Instituto Nacional do Seguro Social (INSS), seja nos Regimes Próprios de Previdência Social (RPPS) dos funcionários públicos.

Mudanças demográficas, como a redução nas taxas de fecundidade e de mortalidade, com o consequente envelhecimento da população tornam ainda mais necessária a discussão sobre a possível implantação de reformas no sistema, que visem à promoção do equilíbrio entre as receitas e despesas. (Giambiagi et al. 2007:182).

Neste contexto, as reformas previdenciárias implantadas durante o mandato do presidente Fernando Henrique Cardoso (FHC), concretizadas por meio da Emenda Constitucional 20 (EC20), da Lei 9.876/99 e do Decreto 3.265/99, possuíam o objetivo de estabelecer o equilíbrio financeiro e atuarial do RGPS do INSS. De maneira complementar, as Emendas Constitucionais 41 e 47 foram promulgadas no governo Lula, tendo como foco principal os RPPS.

Para um sistema previdenciário de repartição simples, regime adotado pelo RGPS, pelo qual os indivíduos atualmente ativos no mercado de trabalho, por meio de suas contribuições à previdência social, financiam os benefícios dos atuais inativos, a questão do envelhecimento da população produz reflexos tanto no fluxo de benefícios, como no de contribuições.

O aumento do número de idosos na população deve representar, ceteris paribus, um aumento de gastos para a previdência, pois há uma ampliação do volume de benefícios previdenciários. Consequentemente, uma população com poucos indivíduos ativos no mercado de trabalho, tende a apresentar dificuldades no financiamento de benefícios de aposentadoria, já que a proporção de participantes ativos no sistema será relativamente pequena quando comparada à de inativos, implicando em uma taxa de dependência elevada.

O artigo 201 da Constituição Federal, com redação dada pela Emenda Constitucional 20, que prevê o equilíbrio financeiro e atuarial do sistema previdenciário, trata da regra de cálculo de benefício de aposentadoria. O detalhamento do cálculo é feito por meio da Lei 9.876/99, que apresenta o fator previdenciário, cujo objetivo é o de aumentar a justiça atuarial do sistema, sendo que sua utilização no cálculo de benefício será obrigatória para as aposentadorias por tempo de contribuição, e opcional para as aposentadorias por idade.

Assim, uma pessoa que contribuir para o INSS por mais tempo, terá um fator previdenciário maior, e consequentemente, terá direito a uma aposentadoria de valor elevado. Logo, o fator previdenciário possui dois objetivos: o de promover o 
equilíbrio atuarial do sistema e o de inibir as aposentadorias precoces (principalmente aposentadorias por tempo de contribuição).

Em que pesem a importância da Emenda 20, da criação do fator previdenciário (Delgado et al. 2006) e das Emendas 41 e 47 (Souza et al. 2006), ainda restam duas lacunas importantes na literatura sobre previdência social no Brasil. A primeira refere-se ao fato de que a maioria das contribuições ao tema pode ser classificada como fiscalista.

Isto significa que o foco destes trabalhos são as questões fiscais, com projeções de receitas e despesas previdenciárias agregadas para todas as coortes de contribuintes e beneficiários ao longo de tempo.

Poucos trabalhos abordam a questão distributiva, na qual o foco principal são os impactos distributivos que os sistemas previdenciários podem ter, particularmente em termos intrageracionais. Ou seja, indivíduos com características diferentes (gênero, idade de entrada no mercado de trabalho, idade de aposentadoria, entre outros) podem ser afetados de maneira distinta pela previdência social.

Uma exceção digna de nota é o trabalho de Zorzin (2008), que aborda a relação entre previdência social e desigualdade racial. A segunda lacuna está relacionada ao fato de que algumas das contribuições (por exemplo, Giambiagi e Afonso 2009) não levam explicitamente em consideração os riscos biométricos (dados pelas probabilidades de morte a cada idade) associados aos fluxos de contribuições e de recebimento dos benefícios previdenciários. Estes riscos podem ser bastante relevantes e sua incorporação pode tornar os modelos e resultados mais precisos, fornecendo subsídios aos formuladores de políticas previdenciárias.

Tendo como base esse quadro do sistema previdenciário, neste artigo busca-se modelar um benefício do RGPS, a aposentadoria por tempo de contribuição (ATC), com o emprego de técnicas da matemática atuarial. Ou seja, incorpora-se aqui o risco biométrico aos fluxos de contribuições e benefícios previdenciários.

O objetivo é calcular para o caso brasileiro alguns parâmetros mundialmente utilizados na análise dos sistemas previdenciários, como as taxas de reposição, alíquotas atuarialmente justas e os valores presentes líquidos dos benefícios e das contribuições, para diferentes combinações de parâmetros, como por exemplo, gênero, período contributivo e idade de aposentadoria. Os resultados obtidos permitem que se possa analisar impactos distributivos oriundos das políticas previdenciárias, bem como comparar o Brasil com outros países.

Além desta introdução, este artigo tem mais cinco seções. A segunda seção traz uma breve revisão da literatura sobre o tema. A terceira seção apresenta o modelo atuarial adotado, por meio do qual são modelados os fluxos de contribuições e benefícios previdenciários. Na seção subsequente são apresentados os resultados dos parâmetros previdenciários calculados. Na quinta 
seção é feita uma extensão dos cálculos, com a modificação em uma variável chave do modelo. Por fim, na sexta seção são apresentadas as conclusões e considerações finais.

\section{Revisão da literatura}

As reformas na previdência social durante os governos FHC (1994-2002), com a Emenda Constitucional 20 (EC20) e a lei do fator previdenciário, e Lula (20032010), com as Emendas Constitucionais 41 e 47, têm sido temas frequentemente abordados na literatura nacional, como em Afonso et al. (2006) e Souza et al. (2006).

Delgado et al. (2006) avaliam os impactos da introdução do fator previdenciário no cálculo dos benefícios do INSS como meio de promover a justiça atuarial do sistema, ressaltando a elevação das médias das idades de aposentadoria após a introdução do fator (variação de 4,7\% para os homens e 5,1\% para as mulheres).

Segue a mesma linha o trabalho de Ribeiro e Fígoli (2008), que ressalta o privilégio às mulheres dado pelo sistema previdenciário, devido à utilização de uma única expectativa de sobrevida no cálculo do fator. Este fato faz com que o seu fator previdenciário seja mais alto do que se fosse empregada a expectativa de vida feminina e não a de ambos os sexos.

A precocidade na concessão do benefício de aposentadoria por tempo de contribuição é abordada nos trabalhos de Giambiagi et al. (2004) e Giambiagi et al. (2007). Ambos os trabalhos defendem a adoção de uma idade mínima para a concessão da ATC: 55 anos para as mulheres e 60 anos para os homens, como meio de ampliar o período contributivo. Giambiagi et al. (2004) ainda apresentam algumas propostas de mudança, dentre as quais uma das mais importantes é a eliminação da diferença de cinco anos no período contributivo entre os homens e mulheres.

Giambiagi e Afonso (2009) calculam a alíquota de equilíbrio atuarial do sistema previdenciário, para uma combinação de variáveis como gênero, gênero, nível educacional e tempo de contribuição. Uma das principais conclusões dos autores é que a alíquota de $31 \%$ atualmente vigente no país é excessiva para benefícios tipicamente previdenciários.

No entanto, o modelo empregado neste artigo não inclui explicitamente em seus cálculos o risco demográfico, variável relevante em cálculos previdenciários. Está implícito nos cálculos que os indivíduos analisados sobreviveram ao período de diferimento (período contributivo) e vêm a falecer após alguns de anos de recebimento da aposentadoria. A não inclusão do risco faz com que o modelo possa ser compreendido como um modelo ex-post em que se olha retrospectivamente para as contribuições efetuadas e benefícios recebidos. 
Ficam latentes duas questões em aberto para a agenda de pesquisa em previdência social. Será possível modelar de forma simples, com o emprego da matemática atuarial, um benefício previdenciário (no caso a ATC)? A inclusão do risco biométrico, por meio de matemática atuarial altera fundamentalmente os resultados anteriores, particularmente aqueles relatados em Giambiagi e Afonso $(2009) ?$

Tendo em vista estas questões, este artigo tem por objetivos calcular as taxas de reposição previdenciária e as alíquotas de equilíbrio atuarial para diversas combinações de parâmetros de gênero, renda, taxa de desconto e idade de ingresso no sistema previdenciário. Adicionalmente também são calculados os valores presentes esperados de contribuições e de benefícios.

\section{Metodologia}

Nesta seção é desenvolvido um modelo atuarial simples para o cálculo das contribuições e dos benefícios referentes à aposentadoria por tempo de contribuição (ATC), concedida pelo RGPS. Inicialmente apresenta-se a metodologia de cálculo das contribuições. A seguir explicita-se o cálculo dos benefícios, com base nas regras do INSS. Posteriormente é feito o cálculo das alíquotas de contribuição. Para tal modelagem é empregado o conceito de anuidades, bastante empregado nos cálculos atuariais.

\section{Contribuições}

De forma genérica um regime previdenciário de repartição simples funciona de maneira relativamente simples. Um indivíduo representativo entra no mercado de trabalho aos $\mathrm{x}$ anos de idade. Durante $\mathrm{n}$ anos este indivíduo irá trabalhar $\mathrm{e}$ contribuir ao sistema previdenciário. Portanto, ao se aposentar, terá a idade de $\mathrm{x}$ $+n-1$ anos. Na idade $x$ sua renda e sua contribuição serão expressas, respectivamente, por $W_{x}$ e $C_{x}$; na idade $x+1$, estes termos serão $W_{x+1}$ e $C_{x+1} e$ assim sucessivamente até $W_{x+n-1}$ e $C_{x+n-1}$.

Quatro hipóteses estão implícitas neste argumento. A primeira é que o trabalhador começa a contribuir já no início do ano em que completa seu x-ésimo aniversário A segunda é que o trabalhador irá se aposentar tão logo atenda as condições de elegibilidade previstas para a concessão do benefício. E a aposentadoria significa que o indivíduo deixa o mercado de trabalho. A terceira hipótese é que não há períodos de desemprego ou desalento, de forma que o período contributivo corresponde exatamente aos $n$ anos do período laboral. Finalmente, a quarta hipótese é que as contribuições são feitas anualmente e não mensalmente, como de fato ocorre. 
Tal simplificação não altera os resultados do trabalho. Deve ser notado que o modelo descrito anteriormente de forma simplificada descreve de maneira adequada os benefícios programáveis, como a aposentadoria por tempo de contribuição do INSS, objeto deste trabalho. Outros tipos de benefícios, de cunho assistencial ou de risco, não fazem parte do escopo do artigo. A Figura 1 apresenta os fluxos de contribuições e benefícios do modelo em questão.

Figura 1. Fluxos previdenciários: contribuições e benefícios.

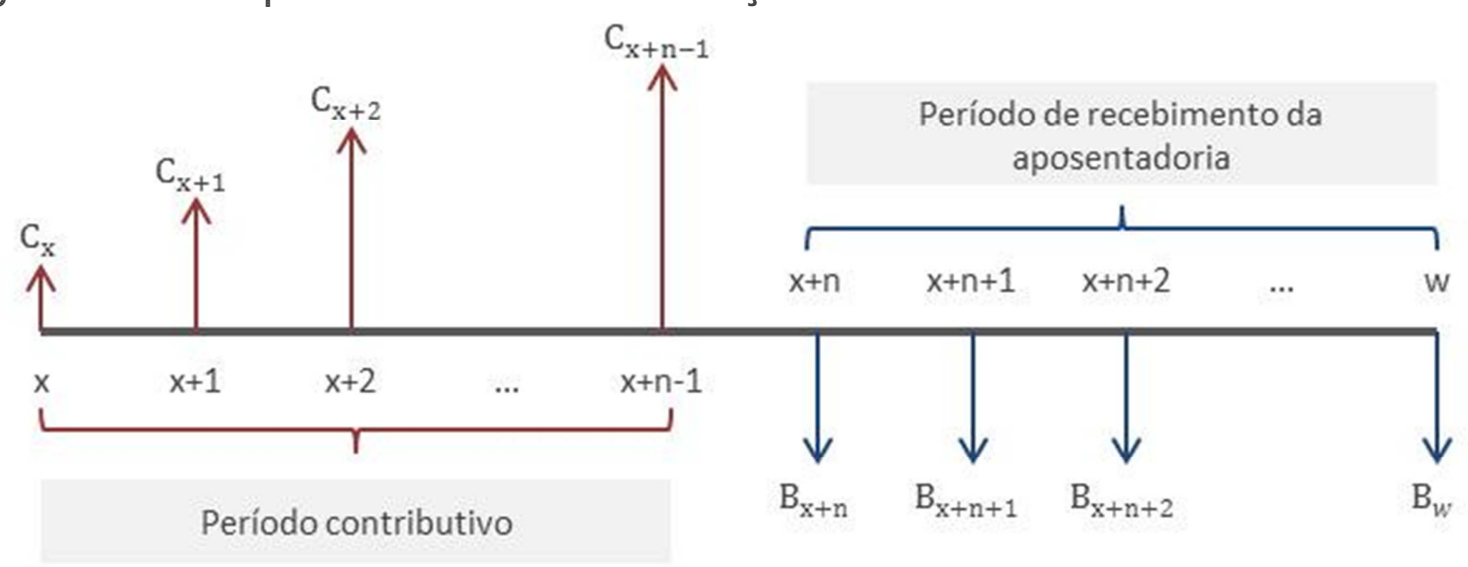

Fonte: elaboração dos autores.

Na matemática financeira usual, para que o fluxo contributivo distribuído ao longo do tempo seja trazido a valor presente para a idade $x$, período de início das contribuições, é necessário empregar-se uma taxa de desconto anual i. Desta forma a contribuição do t-ésimo período (mensurado em anos, contado a partir da idade $\mathrm{x}$ ) deve ser multiplicada por $v^{t}$, conforme definido pela Equação 1 :

\section{Equação 1}

$$
v^{t}=\frac{1}{(1+i)^{t}}
$$

Na matemática atuarial, conforme Jordan (1991:37), à taxa de desconto empregada na matemática financeira deve ser incorporado um componente de risco biométrico. De forma genérica, este é dado pela probabilidade de um indivíduo de idade $x$ completar $x+t$ anos, sendo representado por $P_{x}$, dado pela Equação 2. Nesta expressão $l_{x}$ representa o número de indivíduos de uma coorte hipotética vivos com idade $x$ e $l_{x+t}$ o número de indivíduos desta coorte que completaram a idade $x+t$. 


\section{Equação 2}

$$
\boldsymbol{P}_{x}=\frac{\mathrm{l}_{\mathrm{x}+\mathrm{t}}}{\mathrm{l}_{\mathrm{x}}}
$$

De forma análoga, a probabilidade oposta à de sobrevivência, ou seja, a probabilidade que o indivíduo venha falecer em $t$ anos é mensurável por meio do cálculo atuarial de ${ }_{t} q_{x}$, em que $d_{x}$ representa a quantidade de indivíduos da coorte hipotética que morreram entre as idades $x$ e $x+t$ :

Equação 3

$$
{ }_{t} \boldsymbol{q}_{x}=\frac{d_{x}}{l_{x}}
$$

Portanto, de acordo com os princípios de matemática atuarial, cada contribuição $C_{x}$ tem que ser multiplicada por um fator $v^{t} \times{ }_{t} p_{x}$.

A seguir devem ser estabelecidos os parâmetros para mensurar as contribuições para o RGPS. O primeiro parâmetro é a alíquota de contribuição $c$. No Brasil, para os trabalhadores assalariados do setor privado a contribuição ao sistema previdenciário é feita tanto pelo empregado, quanto pelo empregador.

A alíquota de contribuição do empregador é de $20 \%$ sobre a totalidade do rendimento bruto do empregado. Já a alíquota incidente sobre o empregado depende de seu rendimento mensal bruto, com um valor limite, conforme exposto na Tabela 1.

É necessário lembrar que desde 1987 há uma sobrealíquota de 2,5\% incidente sobre os empregadores do setor financeiro. Esta exceção à regra geral de contribuição não será analisada neste trabalho. De maneira similar, também não serão tratados neste trabalho os casos dos trabalhadores por conta-própria, cujas regras de contribuição também são diferenciadas. Seguindo a nomenclatura do INSS, a renda bruta mensal é denominada Salário de Contribuição.

Assim, a alíquota de contribuição c é dada pela soma das alíquotas incidentes sobre o empregador e sobre o trabalhador, respeitando-se no caso do empregador os limites apresentados na Tabela 1. Os valores apresentados foram definidos de forma retroativa a janeiro de 2010, pela portaria interministerial MPS/MF 333, de 29 de junho de 2010. 
Tabela 1. Alíquotas de contribuição do empregado por faixa de renda.

$\begin{array}{cc}\text { Renda } Y(R \$ / \text { mês }) & \text { Alíquota de contribuição (\%) } \\ Y \leq 1.040,22 & 8,00 \\ 1.040,23 \leq Y \leq 1.733,70 & 9,00 \\ 1.733,71 \leq Y \leq 3.467,40 & 11,00\end{array}$

Fonte: Portaria 333. Ministério da Previdência Social e Ministério da Fazenda. Valores vigentes desde janeiro de 2010.

A etapa seguinte consiste na delimitação do período contributivo necessário à obtenção da ATC. De acordo com a legislação atualmente vigente, os homens podem pleitear a ATC após 35 anos de contribuição. Já para as mulheres o período contributivo é de 30 anos. Em ambos os casos não há limite mínimo de idade estabelecido.

O próximo passo refere-se à evolução temporal da renda do empregado. Supõese que este terá aumentos salariais reais constantes a uma taxa anual $r$ ao longo de sua vida ativa e do seu período contributivo. Desta forma, sendo $W_{x}$ sua renda inicial (na idade $x$ ), sua renda após $t$ períodos será dada por:

Equação 4

$$
W_{t}=W_{x}(1+r)^{t-x}
$$

Partindo do exposto até o momento, é possível calcular o valor presente das contribuições (VPC). O VPC é obtido multiplicando-se a contribuição de cada período de tempo com o fator de desconto composto dado por $v^{t} \times{ }_{t} p_{x}$, cujo objetivo é trazer a valor presente uma série de pagamentos, que serão efetuados durante um período de $n$ anos, pré-estabelecido na legislação (conforme definido anteriormente).

As contribuições podem ser modeladas por meio de uma formulação atuarial denominada anuidade imediata temporária antecipada variável (visto que há crescimento real da renda) $\ddot{a}_{x \bar{n}}$. Desta maneira, o VPC é expresso da seguinte maneira:

\section{Equação 5}

$$
\boldsymbol{V P C}=\ddot{a}_{x \bar{n} \mid} \cdot c W_{t}=\sum_{t=0}^{n-1} v^{t} \cdot{ }_{t} p_{x} \cdot c W_{t}=\sum_{t=0}^{n-1} \frac{1}{(1+i)^{t}} \cdot \frac{l_{x+t}}{l_{x}}
$$




\section{Benefícios}

Uma vez explicitada a fórmula de cálculo das contribuições, passa-se ao cálculo da aposentadoria. O fluxo de benefícios é dado pelo valor da aposentadoria que o indivíduo receberá do RGPS, após ter contribuído para o sistema por um período pré-estabelecido em função do gênero, até seu falecimento com idade terminal $\omega$. Pode-se entender o período contributivo como um período de diferimento até o início da inatividade, e conseqüente percepção de benefícios.

A matemática atuarial contempla esse período de diferimento com uma formulação denominada anuidade vitalícia postecipada diferida por $n$ anos, representada por ${ }_{n} \mid a_{x}$. Esta anuidade é postecipada, pois o primeiro recebimento do benefício será feito no final do último ano de contribuição (ou no início do ano seguinte) e vitalícia, pois os pagamentos acontecerão enquanto o aposentado estiver vivo.

Essa anuidade representa a série de pagamentos vitalícios trazida a valor presente, que será iniciada após $n$ anos de contribuição. Assim, multiplicada pelo valor do benefício de aposentadoria traz como resultado o valor atual do montante necessário para o pagamento dos benefícios vitaliciamente, definido como valor presente dos benefícios (VPB).

O valor do benefício de aposentadoria é denominado pelo INSS como salário de benefício $(S b)$. Seu cálculo é feito em duas etapas. Inicialmente calcula-se a média M dos 80\% maiores salários de contribuição entre junho de 1994 e a data de aposentadoria. A segunda etapa é o cálculo do Fator Previdenciário, expresso pela Equação 6.

Nesta equação, Tc é o tempo de contribuição ao RGPS (30 anos para mulheres e 35 anos para os homens); $a$ é a alíquota de contribuição (fixada em 0,31 ); Es é a expectativa de sobrevida no momento da aposentadoria e Id é a idade de aposentadoria. Obviamente, pela formulação ad hoc do fator, ceteris paribus, quanto mais elevada a idade de aposentadoria, menor a expectativa de sobrevida, mais elevado o fator e, portanto, maior o salário de benefício (Sb).

Equação 6

$$
\boldsymbol{f}=\frac{T c \cdot a}{E s}\left(1+\frac{I d+T c \cdot a}{100}\right)
$$

Finalmente, o valor da aposentadoria, ou seja, o salário de benefício $S b$, é dado pela Equação 7 : 


\section{Equação 7}

$$
\boldsymbol{S b}=M \cdot f
$$

Uma vez apresentada a forma de cálculo do salário de benefício, o passo seguinte é o cálculo do VPB, de forma similar ao procedimento efetuado na seção anterior para VPC, conforme apresentado na Equação 8. Supõe-se aqui, em consonância com política do Ministério da Previdência Social, que o valor real do benefício será mantido ao longo do tempo. Neste tipo de modelo, isso corresponde a supor constante o valor de $S b$.

\section{Equação 8}

$$
V P B=S b \cdot{ }_{n} \mid a_{x}=S b \cdot \sum_{t=n}^{\omega} v^{t} \cdot{ }_{t} p_{x}
$$

Finalmente, com base nas variáveis construídas anteriormente, é possível calcular-se o valor presente líquido dos benefícios previdenciários. O VPL é dado pela diferença entre VPB e VPC, conforme descrito na Equação 9. O VPL é inspirado no conceito de Social Security Net Worth (SSWN) que aparece pela primeira vez no trabalho pioneiro de Feldstein (1974).

Equação 9

$$
V P L=V P B-V P C
$$

\section{Resultados}

Uma vez apresentado o modelo teórico, nesta seção é descrito o procedimento empírico efetuado e são apresentados os resultados dos cálculos do VPB e VPC para diversas combinações de parâmetros. A seguir são calculados o valor presente líquido dos benefícios previdenciários (VPL) e a taxa de reposição de aposentadoria (TR). Por fim, é calculada a alíquota atuarialmente justa de contribuição. 


\section{Valor presente das contribuições (VPC)}

O primeiro conjunto de resultados refere-se ao valor das contribuições segundo o gênero do contribuinte. Na análise, conforme descrito anteriormente, considerase apenas o benefício integral da aposentadoria por tempo de contribuição, cuja requisito de elegibilidade são 35 anos de contribuição para os homens e 30 anos para as mulheres.

Os cálculos são efetuados para diversas idades de início de contribuição $x$, de 16 (idade mínima definida pelo INSS para início das contribuições) até 20 anos. Para que o fluxo contributivo possa ser trazido a valor presente são utilizadas duas possíveis taxas de desconto i, 3\% a.a. e 4\% a.a.

A escolha destas taxas tem como base a expectativa de taxa de juros real pagas pelos títulos públicos. Em um ano de crescimento econômico bastante elevado, como 2010, a expectativa de inflação medida pelo Índice de Preços ao Consumidor Amplo (IPCA) é da ordem de 5,5\% a.a. Como a taxa Selic nominal, no momento em que este texto estava sendo finalizado, era de 5,5\% a.a., chega-se a uma taxa de juros real anual próxima a 4,5\%. Espera-se que ao longo dos próximos anos, este valor venha a se reduzir para uma faixa de 3 a $4 \%$, valores adotados no texto.

Como parâmetro de renda inicial do contribuinte $\left(W_{x}\right)$ é utilizado o número de salários mínimos (SM) percebidos no início da vida laboral de cada trabalhador. Os cálculos são feitos para os valores de 1 SM e 3 SM. Supõe-se ainda que a renda cresça a uma taxa anual $r$ de $2 \%$ a.a. Para a alíquota de contribuição c é utilizada a regra prevista na legislação, apresentada na Tabela 1. Finalmente, para as probabilidades de sobrevivência a cada idade são usados os dados das Tábuas Completas de Mortalidade 2008, para homens e mulheres, divulgadas anualmente pelo IBGE.

A Tabela 2 apresenta os resultados de VPC para homens e mulheres que tenham iniciado sua vida laboral com uma renda de 1 SM mensal. No primeiro ano sua renda será igual a $13 \times \mathrm{R} \$ 510,00=\mathrm{R} \$ 6.630,00$ (devido ao $13^{\circ}$ salário).

No segundo ano a renda aumenta $2 \%$ a.a. e assim sucessivamente. Os fluxos de contribuições e benefícios são mensais. Neste texto, todos os valores são supostos anuais, devido à imputação das probabilidades de morte por idade. É razoável supor que esta suposição tem impactos insignificantes sobre os resultados e conclusões aqui apresentados.

Como já esperado, o montante de contribuições do sexo masculino é superior ao montante de contribuições efetuadas durante a vida ativa pelas mulheres. Tal diferença é justificada pela diferença de cinco anos no período contributivo dos gêneros. A Tabela 3 apresenta resultados similares, para uma renda mensal inicial de três SM. 
Tabela 2. Valor presente das contribuições (VPC) por gênero e taxa de desconto. Taxa de crescimento da renda $=2 \%$ a.a. Renda mensal inicial $=1$ SM (Valores em reais).

\begin{tabular}{cccc|ccc}
\hline \multicolumn{4}{c|}{ Mulheres } & \multicolumn{4}{c}{ Homens } \\
\hline $\begin{array}{c}\text { Início do período } \\
\text { contributivo } \\
\text { (anos) }\end{array}$ & $\begin{array}{c}\text { Taxa de Desconto } \\
\text { (\% a.a.) }\end{array}$ & $\begin{array}{c}\text { Início do período } \\
\text { contributivo } \\
\text { (anos) }\end{array}$ & \multicolumn{2}{c}{$\begin{array}{c}\text { Taxa de Desconto } \\
\text { (\% a.a.) }\end{array}$} \\
\hline 16 & 3 & 4 & 16 & 5 & 4 \\
\hline 17 & $47.966,84$ & $42.170,29$ & $52.770,23$ & $45.582,14$ \\
\hline 18 & $47.928,75$ & $42.139,21$ & 17 & $52.642,58$ & $45.479,12$ \\
\hline 19 & $47.888,53$ & $42.106,47$ & 18 & $52.519,29$ & $45.380,21$ \\
\hline 20 & $47.845,31$ & $42.071,33$ & 19 & $52.398,14$ & $45.283,59$ \\
\hline & $47.798,33$ & $42.033,16$ & 20 & $52.276,91$ & $45.187,45$ \\
\hline
\end{tabular}

Fonte: cálculos dos autores.

Tabela 3. Valor presente das contribuições (VPC) por gênero e taxa de desconto. Taxa de crescimento da renda $=2 \%$ a.a. Renda mensal inicial=3 SM (Valores em reais).

\begin{tabular}{|c|c|c|c|c|c|}
\hline \multicolumn{3}{|c|}{ Mulheres } & \multicolumn{3}{|c|}{ Homens } \\
\hline \multirow{2}{*}{$\begin{array}{l}\text { Início do período } \\
\text { contributivo } \\
\text { (anos) }\end{array}$} & \multicolumn{2}{|c|}{$\begin{array}{c}\text { Taxa de Desconto } \\
\text { (\% a.a.) }\end{array}$} & \multirow{2}{*}{$\begin{array}{l}\text { Início do período } \\
\text { contributivo } \\
\text { (anos) }\end{array}$} & \multicolumn{2}{|c|}{$\begin{array}{c}\text { Taxa de Desconto } \\
(\% \text { a.a.) }\end{array}$} \\
\hline & 3 & 4 & & 3 & 4 \\
\hline 16 & $156.617,50$ & $137.440,29$ & 16 & $172.582,31$ & $148.782,79$ \\
\hline 17 & $156.491,28$ & $137.337,34$ & 17 & $172.160,24$ & $148.442,41$ \\
\hline 18 & $156.357,93$ & $137.228,84$ & 18 & $171.752,41$ & $148.115,48$ \\
\hline 19 & $156.214,62$ & $137.112,37$ & 19 & $171.351,47$ & $147.795,98$ \\
\hline 20 & $156.058,87$ & $136.985,84$ & 20 & $170.950,05$ & $147.477,84$ \\
\hline
\end{tabular}

Fonte: cálculos dos autores.

\section{Valor presente dos benefícios (VPB)}

O cálculo do VPB é feito em três etapas, de forma similar relacionada ao procedimento de cálculo do VPC. A primeira delas é o cálculo da anuidade atuarial, que contempla a probabilidade de sobrevivência após o início de recebimento do benefício de aposentadoria.

Neste caso a o recebimento do benefício de aposentadoria começa no ano seguinte ao final do período contributivo e é limitado a 80 anos de idade (última idade da Tábua Completa de Mortalidade 2008 - Ambos os sexos, do IBGE). As taxas de desconto utilizadas também são de 3\% e $4 \%$ a.a.

A segunda etapa consiste no cálculo do salário de benefício (Sb). De acordo com as regras vigentes, o salário de benefício corresponde à média M dos $80 \%$ maiores salários de contribuição multiplicada pelo fator previdenciário f.

Dada a hipótese de taxa de crescimento de renda constante ao longo do período contributivo, os $80 \%$ maiores salários de contribuição constituem também as 
80\% últimas remunerações do indivíduo. O salário de contribuição está limitado ao teto previdenciário de $R \$ 3.416,54$ ao mês ( $R \$ 44.415,02$ ao ano), limite este aplicável às contribuições do empregado. No caso do empregador, não há limite.

O cálculo da média dos $80 \%$ maiores salários de contribuição é feito com base no período contributivo, diferenciado em função do gênero. Assim, para as mulheres, que contribuem 30 anos para o sistema previdenciário, é utilizado o intervalo contributivo que vai do sétimo ao trigésimo ano de contribuição. Para os homens ( 35 anos de contribuição) o intervalo é do oitavo ao trigésimo quinto ano contributivo.

A terceira e última etapa corresponde ao cálculo do fator previdenciário, usando a Equação 6. No caso das mulheres, a legislação prevê um bônus de 5 anos no tempo de contribuição TC empregado no cálculo do fator. Por exemplo, para uma mulher que contribui para a Previdência por 30 anos e se aposenta aos 50 anos de idade, é como se a mesma tivesse contribuído para o sistema por 35 anos.

Assim, multiplicado o fator previdenciário pela média dos $80 \%$ maiores salários de contribuição obtêm-se o salário de benefício, que por sua vez, é multiplicado pela anuidade atuarial, obtendo-se VPB.

Conforme descrito anteriormente, todos os resultados deste artigo referem-se a dois casos particulares, nos quais a renda inicial dos indivíduos corresponde a 1 ou 3 SM por mês ( $\$ \$ 6.630,00$ e $\mathbf{R} \$ 19.890,00$ ao ano, respectivamente, já incluindo o $13^{\circ}$ salário). A renda destes trabalhadores aumenta, em termos reais, $2 \%$ a.a.

As Tabelas 4 e 5 apresentam os valores de salários de benefícios mensais para rendas iniciais de 1 e 3 salários mínimos, para homens e mulheres, para as rendas iniciais escolhidas, de 1 e 3 SM, de acordo com a metodologia de cálculo descrita anteriormente. Ou seja, são os valores da aposentadoria destes trabalhadores representativos escolhidos. As tabelas apresentam também os valores do fator previdenciário destes grupos. Todos os valores são calculados para uma taxa de desconto de $3 \%$ a.a.

Tabela 4. Salário de benefício (SB) e fator previdenciário por gênero. Taxa de crescimento da renda $=2 \%$ a.a. Renda Inicial $=1$ SM (Valores em reais).

\begin{tabular}{cccc|cccc}
\hline \multicolumn{1}{c}{$\begin{array}{c}\text { Idade de } \\
\text { início de } \\
\text { contribuição }\end{array}$} & $\begin{array}{c}\text { Idade de } \\
\text { aposentadoria }\end{array}$ & Fator & $\begin{array}{c}\text { Salário de } \\
\text { Benefício } \\
\text { (R/mês) }\end{array}$ & $\begin{array}{c}\text { Idade de } \\
\text { início de } \\
\text { contribuição }\end{array}$ & $\begin{array}{c}\text { Homens } \\
\text { Idade de } \\
\text { aposentadoria }\end{array}$ & $\begin{array}{c}\text { Fator } \\
\text { Salário de } \\
\text { Benefício } \\
\text { (R\$/mês) }\end{array}$ \\
\hline 16 & 46 & 0,528 & 384,61 & 16 & 51 & 0,528 & 409,54 \\
\hline 17 & 47 & 0,546 & 397,43 & 17 & 52 & 0,648 & 502,26 \\
\hline 18 & 48 & 0,564 & 410,86 & 18 & 53 & 0,672 & 520,61 \\
\hline 19 & 49 & 0,584 & 424,95 & 19 & 54 & 0,696 & 539,90 \\
\hline 20 & 50 & 0,604 & 439,76 & 20 & 55 & 0,723 & 560,19 \\
\hline
\end{tabular}

Fonte: elaboração dos autores. 
Tabela 5. Salário de benefício (SB) e fator previdenciário por gênero. Taxa de crescimento da renda $=2 \%$ a.a. Renda Inicial $=3$ SM (Valores em reais).

\begin{tabular}{|c|c|c|c|c|c|c|c|}
\hline \multicolumn{4}{|c|}{ Mulheres } & \multicolumn{4}{|c|}{ Homens } \\
\hline $\begin{array}{c}\text { Idade de } \\
\text { início de } \\
\text { contribuição }\end{array}$ & $\begin{array}{c}\text { Idade de } \\
\text { aposentadoria }\end{array}$ & Fator & $\begin{array}{l}\text { Salário de } \\
\text { Benefício } \\
\text { (R\$/mês) }\end{array}$ & $\begin{array}{c}\text { Idade de } \\
\text { início de } \\
\text { contribuição }\end{array}$ & $\begin{array}{c}\text { Idade de } \\
\text { aposentadoria }\end{array}$ & Fator & $\begin{array}{l}\text { Salário de } \\
\text { Benefício } \\
\text { (R\$/mês) }\end{array}$ \\
\hline 16 & 46 & 0,528 & $1.153,84$ & 16 & 51 & 0,528 & $1.228,62$ \\
\hline 17 & 47 & 0,546 & $1.192,29$ & 17 & 52 & 0,648 & $1.506,79$ \\
\hline 18 & 48 & 0,564 & $1.232,58$ & 18 & 53 & 0,672 & $1.561,82$ \\
\hline 19 & 49 & 0,584 & $1.274,86$ & 19 & 54 & 0,696 & $1.619,70$ \\
\hline 20 & 50 & 0,604 & $1.319,27$ & 20 & 55 & 0,723 & $1.680,57$ \\
\hline
\end{tabular}

Fonte: elaboração dos autores.

Os resultados da Tabela 4 devem ser olhados com atenção. A legislação vigente prevê que o valor do benefício de aposentadoria não poderá ser inferior a 1 SM por mês. No entanto, como é possível notar na Tabela 4, para todas as idades propostas, as mulheres que iniciam sua vida contributiva com um salário mínimo mensal, deveriam receber um salário de benefício inferior ao mínimo previsto.

O mesmo acontece com os homens para as idades de 16 e 17 anos. Provavelmente este fato é explicado por uma conjunção de fatores. O mais importante deles é a influência do fator previdenciário no valor do benefício. Como a idade de aposentadoria máxima na tabela para as mulheres ( 50 anos) é bastante baixa, o fator tem valor bastante inferior à unidade, o que reduz sobremaneira o valor do benefício. Raciocínio análogo aplica-se aos homens.

Adicionalmente pode-se avaliar que as pessoas que iniciaram cedo sua vida ativa, com rendimento igual a 1 SM são provavelmente trabalhadores de baixa qualificação. Há uma probabilidade de que estes trabalhadores passem sua vida ativa transitando entre os setores formal e informal da economia, o que fará com que se aposentem com uma idade mais elevada e, portanto, com um fator previdenciário mais elevado.

Ou, provavelmente, devido a estas transições no mercado de trabalho, acabem se aposentando por idade e não por tempo de contribuição. Esta possibilidade não é contemplada neste artigo, visto que uma das hipóteses iniciais é que as pessoas iniciam e terminam sua carreira no setor formal da economia. Adicionalmente, pode haver ainda períodos de desemprego, também não incorporados à metodologia deste trabalho.

Desta maneira, feita esta restrição, uma alteração nos dados da Tabela 4 deve ser feita para que os resultados aqui apresentados mantenham-se em consonância com o texto legal. Para todos os cálculos subsequentes, nos casos em que o salário de benefício calculado for inferior a 1 SM mensal ( $\$ \$ 510,00)$, seu valor será alterado para 1 SM. Isso será feito, conforme apontado, nos valores reportados na Tabela 4 para todas as idades iniciais de contribuição das mulheres e para os homens que iniciaram sua vida ativa aos 16 ou 17 anos. 
A seguir, nas Tabelas 6 e 7 apresentam-se os valores de VPB para homens e mulheres, diferentes idades de início de contribuição e taxas de desconto. É possível notar que o VPB das mulheres é superior ao dos homens para todas as idades e taxas de desconto propostas. Tal fato pode ser explicado pela conjugação de dois fatores que possuem sentidos opostos.

De um lado, um período contributivo menor faz com que as mulheres se aposentem com idades mais baixas que os homens, estendendo assim o período de percepção de benefícios, já que a expectativa de sobrevida no momento da aposentadoria será maior.

Por outro lado, a idade de início de percepção de benefício relativamente menor faz com que, conforme já descrito anteriormente, o fator tenha um valor baixo, o que resulta em um salário de benefício $\mathrm{Sb}$ menor. Os dados apresentados permitem inferir que o primeiro efeito possui uma força maior que o segundo, de tal maneira que o VPB das mulheres é maior que o dos homens.

Tabela 6. Valor presente dos benefícios (VPB) por gênero e taxa de desconto. Taxa de crescimento da renda $=2 \%$ a.a. Renda Inicial=1 SM (Valores em reais).

\begin{tabular}{|c|c|c|c|c|c|}
\hline \multirow{2}{*}{$\begin{array}{c}\text { Idade de Início } \\
\text { de } \\
\text { Contribuição }\end{array}$} & \multicolumn{2}{|c|}{ Mulheres } & \multirow{2}{*}{$\begin{array}{c}\text { Idade de Início } \\
\text { de } \\
\text { Contribuição }\end{array}$} & \multicolumn{2}{|c|}{$\begin{array}{c}\text { Homens } \\
\text { Taxa de desconto (\% a.a.) }\end{array}$} \\
\hline & 3 & 4 & & 3 & 4 \\
\hline 16 & $50.979,33$ & $33.923,95$ & 16 & $32.990,59$ & $21.335,71$ \\
\hline 17 & $49.821,90$ & $33.248,82$ & 17 & $31.920,98$ & $20.703,21$ \\
\hline 18 & $48.639,64$ & $32.554,06$ & 18 & $31.484,03$ & $20.479,01$ \\
\hline 19 & $47.431,77$ & $31.838,89$ & 19 & $31.498,27$ & $20.548,26$ \\
\hline 20 & $46.197,72$ & $31.102,71$ & 20 & $31.474,01$ & $20.593,19$ \\
\hline
\end{tabular}

Fonte: elaboração dos autores.

Tabela 7. Valor presente dos benefícios (VPB) por gênero e taxa de desconto. Taxa de crescimento da renda $=2 \%$ a.a. Renda Inicial=3 SM (Valores em reais).

\begin{tabular}{|c|c|c|c|c|c|}
\hline \multirow{3}{*}{$\begin{array}{l}\text { Idade de Início } \\
\text { de Contribuição }\end{array}$} & \multicolumn{2}{|c|}{ Mulheres } & \multirow{3}{*}{$\begin{array}{c}\text { Idade de Início } \\
\text { de } \\
\text { Contribuição }\end{array}$} & \multirow{2}{*}{\multicolumn{2}{|c|}{$\begin{array}{c}\text { Homens } \\
\text { Taxa de desconto (\% a.a.) }\end{array}$}} \\
\hline & \multicolumn{2}{|c|}{ Taxa de desconto (\% a.a.) } & & & \\
\hline & 3 & 4 & & 3 & 4 \\
\hline 1 & 115.33 & 76.750 & 16 & 79.476 & 51.39 \\
\hline 1 & 116.4 & 7 & 17 & 94 & 54 \\
\hline 18 & $117.553,78$ & $78.677,65$ & 18 & $94.452,10$ & $61.437,02$ \\
\hline 19 & $118.566,35$ & $79.588,45$ & 19 & $94.494,80$ & $61.644,78$ \\
\hline & 119.50 & $80.456,50$ & 20 & $94.422,04$ & $61.779,56$ \\
\hline
\end{tabular}

Fonte: elaboração dos autores. 


\section{Valor presente líquido dos benefícios previdenciários (VPL)}

Conforme mencionado anteriormente, o VPL é calculado pela diferença entre VPB e VPC (ver Equação 9). As Tabelas 8 e 9 apresentam o cálculo do VPL por gênero e taxas de desconto de $3 \%$ e $4 \%$ a.a., para rendas iniciais de um e três salários mínimos.

É possível constatar que em todos os casos o fluxo de benefícios é inferior ao fluxo de contribuição, exceto para as mulheres com renda inicial de um salário mínimo e idade máxima de 18 anos. Ou seja, para a grande maioria dos indivíduos representativos em análise, o montante esperado de recebimentos associados à ATC é inferior aos pagamentos a serem feitos, feita para ambos os fluxos a ponderação pelo risco biométrico.

Tabela 8. Valor presente líquido (VPL) por gênero e taxa de desconto. Renda Inicial=1 SM (Valores em reais).

\begin{tabular}{|c|c|c|c|c|c|}
\hline \multicolumn{3}{|c|}{ Mulheres } & \multicolumn{3}{|c|}{ Homens } \\
\hline \multirow{2}{*}{$\begin{array}{l}\text { Idade de Início } \\
\text { de Contribuição }\end{array}$} & \multicolumn{2}{|c|}{ Taxa de Desconto } & \multirow{2}{*}{$\begin{array}{l}\text { Idade de Início } \\
\text { de Contribuição }\end{array}$} & \multicolumn{2}{|c|}{ Taxa de Desconto } \\
\hline & $3 \%$ & $4 \%$ & & $3 \%$ & $4 \%$ \\
\hline 16 & $3.012,49$ & $-8.246,34$ & 16 & $-19.779,64$ & $-24.246,43$ \\
\hline 17 & $1.893,14$ & $-8.890,38$ & 17 & $-20.721,60$ & $-24.775,91$ \\
\hline 18 & 751,11 & $-9.552,41$ & 18 & $-21.035,26$ & $-24.901,20$ \\
\hline 19 & $-413,54$ & $-10.232,44$ & 19 & $-20.899,88$ & $-24.735,33$ \\
\hline 20 & $-1.600,61$ & $-10.930,45$ & 20 & $-20.802,90$ & $-24.594,26$ \\
\hline
\end{tabular}

Fonte: elaboração dos autores.

Tabela 9. Valor presente líquido (VPL) por gênero e taxa de desconto. Taxa de crescimento da renda $=2 \%$ a.a. Renda Inicial=3 SM (Valores em reais).

\begin{tabular}{ccc|ccc}
\hline & \multicolumn{3}{c}{ Mulheres } & \multicolumn{3}{c}{ Homens } \\
\hline Idade de Início & \multicolumn{2}{c}{ Taxa de Desconto } & Idade de Início & \multicolumn{2}{c}{ Taxa de Desconto } \\
\cline { 2 - 6 } de Contribuição & $3 \%$ & $4 \%$ & de Contribuição & $3 \%$ & $4 \%$ \\
\hline 16 & $-41.280,07$ & $-60.689,55$ & 16 & $-93.106,28$ & $-97.383,95$ \\
\hline 17 & $-40.016,21$ & $-59.607,28$ & 17 & $-77.849,84$ & $-87.274,87$ \\
\hline 18 & $-38.804,15$ & $-58.551,19$ & 18 & $-77.300,31$ & $-86.678,46$ \\
\hline 19 & $-37.648,27$ & $-57.523,92$ & 19 & $-76.856,68$ & $-86.151,20$ \\
\hline 20 & $-36.554,58$ & $-56.529,34$ & 20 & $-76.528,01$ & $-85.698,29$ \\
\hline
\end{tabular}

Fonte: elaboração dos autores.

Tal fato pode ser justificado pela idade de aposentadoria baixa (de 46 a 50 anos), dado o início do período de contribuição, fazendo com que a expectativa de sobrevida no momento da aposentadoria seja elevada. A lógica é que no caso das mulheres, que iniciam a vida laboral com renda igual a um salário mínimo ao mês (R $\$ 6.630,00$ ao ano), o VPB será superior ao VPC porque neste caso o salário de benefício não atinge o piso legalmente estabelecido de 1 SM (R\$510,00 por mês). 
Nestes casos apontados é necessário que haja o que se pode considerar um subsídio implícito por parte do sistema previdenciário, no valor médio de $\mathbf{R} \$ 98,48$ ao mês (diferença média do salário de benefício calculado para as mulheres na Tabela 4) ou R\$1.280,21 ao ano, segundo o conjunto de idades propostas, para que assim o salário de benefício seja igual ao mínimo previsto na legislação.

\section{Taxa de reposição (TR)}

O passo seguinte é o cálculo de um indicador bastante comum na análise de sistemas previdenciários: a taxa de reposição previdenciária (TR). Este indicador é empregado, por exemplo, nos trabalhos de Fox (1979), Biggs, Brown e Springstead (2005), Michell e Phillips (2006) e Forteza e Ourens (2009).

O cálculo da TR é feito por meio da relação entre os valores da primeira aposentadoria $\left(A_{t+1}\right)$ e da última remuneração do período laboral $\left(W_{t}\right)$, conforme apresentado na Equação 10. A TR pode ser entendida como uma proxy da percepção do indivíduo sobre o sistema previdenciário, visto que tanto o última remuneração, quanto o primeiro benefício encontram-se em momentos do tempo subseqüentes e são facilmente mensuráveis e compreendidos pelas pessoas.

Equação 10

$$
T R=\frac{A_{t+1}}{W_{t}}
$$

As Tabelas 10 e 11 apresentam taxas de reposição de aposentadoria analisadas por gênero, idade de início de contribuição para o sistema previdenciário e para rendas iniciais de um e três salários mínimos, respectivamente. Por meio delas é possível chegar a algumas conclusões. Como esperado, para períodos de contribuição mais longos a taxa de reposição será maior.

As taxas de reposição previdenciária do sexo masculino são superiores ao do sexo oposto, com a mesma exceção anteriormente descrita. Isto também pode ser explicado pela influência de dois efeitos opostos. De um lado, a diferença no período contributivo de cada gênero.

Cabe lembrar, que tal diferença é amenizada pelo bônus de cinco anos que as mulheres possuem no período de contribuição empregado no cálculo do fator previdenciário. Do outro lado, a idade de aposentadoria, também empregada no cálculo do fator, da qual deriva a expectativa de sobrevida ao longo do período de percepção de benefício. 
Assim, como o salário de benefício é inversamente proporcional a expectativa de sobrevida, pode-se concluir que o último efeito possui uma dimensão um pouco maior que o primeiro, reduzindo o salário de benefício no caso das mulheres, que se aposentam com idades mais baixas do que os homens, o que provoca uma redução da reposição previdenciária.

Exceções ao argumento delineado no parágrafo anterior ocorrem com as mulheres que iniciam a vida laboral com renda igual a um salário mínimo e para os homens com mesma renda inicial e que iniciaram a vida ativa aos 16 ou 17 anos.

Estes casos particulares se devem ao fato de que quando estes indivíduos chegam à idade de percepção de benefícios, o salário de benefício calculado a partir das contribuições efetuadas é menor que o salário de benefício mínimo previsto na legislação (um salário mínimo), sendo necessário que o salário de benefício seja subsidiado pela sociedade para que assim atinja ao mínimo legal.

Consequentemente, estas mulheres acabam por receber um salário de benefício superior ao que seria equivalente às suas contribuições durante a vida ativa, o que eleva sua taxa de reposição previdenciária e a mantém constante para todo o conjunto de idades propostas.

Tabela 10. Taxa de reposição (TR) por gênero. Taxa de crescimento da renda $=2 \%$ a.a. Renda Inicial=1 SM (Valores em reais).

\begin{tabular}{ccc}
\hline Idade de Início de Contribuição & Mulheres & Homens \\
\hline 16 & 0,563 & 0,510 \\
\hline 17 & 0,563 & 0,510 \\
\hline 18 & 0,563 & 0,521 \\
\hline 19 & 0,563 & 0,540 \\
\hline 20 & 0,563 & 0,560 \\
\hline
\end{tabular}

Fonte: elaboração dos autores.

Tabela 11. Taxa de reposição (TR) por gênero. Taxa de crescimento da renda $=2 \%$ a.a. Renda Inicial=3 SM (Valores em reais).

\begin{tabular}{ccc}
\hline Idade de Início de Contribuição & Mulheres & Homens \\
\hline 16 & 0,425 & 0,410 \\
\hline 17 & 0,439 & 0,502 \\
\hline 18 & 0,454 & 0,521 \\
\hline 19 & 0,469 & 0,540 \\
\hline 20 & 0,486 & 0,560
\end{tabular}

Fonte: elaboração dos autores. 


\section{Alíquota atuarialmente equilibrada}

Para que o sistema previdenciário seja atuarialmente equilibrado é necessário que o valor presente do fluxo esperado de contribuições (VPC) seja igual ao valor presente esperado do fluxo de benefícios (VPB), ou seja, VPC = VPB.

De forma genérica, o montante de contribuições efetuadas é dado pela multiplicação da renda do indivíduo por uma alíquota previdenciária constante. De forma similar à nomenclatura empregada, pode-se definir VPR como o valor presente esperado do fluxo de renda ao longo da vida ativa, em relação ao qual o montante de contribuições deve ser referenciado. Logo, é preciso encontrar uma alíquota de contribuição atuarialmente equilibrada $\tau_{e q}$, de acordo com a Equação 11.

O conceito subjacente a esta alíquota é similar ao apresentado por Veall (1986) em um ambiente determinista. Para uma exposição mais detalhada sobre justiça atuarial e o desenho de sistemas previdenciários, ver Queisser e Whitehouse (2006).

Equação 10

$$
\tau_{e q}=\frac{V P B}{V P R}
$$

As Tabelas 12 e 13 apresentam as alíquotas de contribuição atuarialmente equilibradas, por gênero, taxa de desconto e idade de início de contribuição. Os resultados permitem algumas conclusões. A primeira delas é que para qualquer combinação proposta, as alíquotas das mulheres são sempre superiores às alíquotas dos homens.

Isto deriva do seu menor período contributivo e maior período de percepção de benefício, dada a expectativa de sobrevida no momento da aposentadoria. Outro fato, já mencionado anteriormente, que contribui para essa diferença, é o bônus de cinco anos que as mulheres possuem no tempo de contribuição empregado no cálculo do fator previdenciário.

A segunda conclusão proposta é que, as alíquotas de contribuição do RGPS (de $28 \%$ a $31 \%$, somando-se as alíquotas do empregado e do empregador) são elevadas para custear um benefício tipicamente previdenciário, como a aposentadoria por tempo de contribuição, se comparadas às alíquotas de equilíbrio apresentadas nas Tabelas 12 e 13, exceto para os casos das mulheres de idade igual a 16 ou 17 anos, com renda inicial de um salário mínimo ao mês, a uma taxa de desconto de $3 \%$ a.a. 
No caso destas mulheres a alíquota de contribuição atualmente vigente mostrase insuficiente para o benefício tipicamente previdenciário aqui analisado, a ATC. Este fato pode ser explicado pela necessidade do subsídio implícito feito pelo sistema previdenciário ao salário de benefício, para que este atinja o mínimo legal.

A exceção não é aplicável aos homens, que revelaram possuir alíquotas atuariais mais que suficientes para benefícios tipicamente previdenciários, o que leva à conclusão de que parte da alíquota contributiva do RGPS (de 28 a 31\%, conforme a faixa de renda) é empregada para o financiamento dos benefícios de risco, como as aposentadorias por invalidez, ou mesmo de outros benefícios programáveis, como a aposentadoria por idade.

Deve ser ressaltado que estes resultados lançam alguma luz sobre as características distributivas do RGPS: se, pessoas que iniciaram sua vida ativa mais tarde e homens têm alíquotas atuarialmente justas mais baixas, então pode-se inferir que há um mecanismo de subsídio intrageracional, em que estes grupos subsidiam os demais contribuintes do RGPS.

Tabela 12. Alíquota atuarialmente justa $\left(\tau_{\mathrm{eq}}\right)$ por gênero. Taxa de crescimento da renda $=2 \%$ a.a. Renda Inicial $=1$ SM.

\begin{tabular}{|c|c|c|c|c|c|}
\hline \multicolumn{3}{|c|}{ Mulheres } & \multicolumn{3}{|c|}{ Homens } \\
\hline \multirow{2}{*}{$\begin{array}{l}\text { Idade de Início } \\
\text { de Contribuição }\end{array}$} & \multicolumn{2}{|c|}{ Taxa de Desconto } & \multirow{2}{*}{$\begin{array}{l}\text { Idade de Início } \\
\text { de Contribuição }\end{array}$} & \multicolumn{2}{|c|}{ Taxa de Desconto } \\
\hline & $3 \%$ & $4 \%$ & & $3 \%$ & $4 \%$ \\
\hline 16 & 0,2976 & 0,2252 & 16 & 0,1750 & 0,1311 \\
\hline 17 & 0,2911 & 0,2209 & 17 & 0,1698 & 0,1275 \\
\hline 18 & 0,2844 & 0,2165 & 18 & 0,1679 & 0,1264 \\
\hline 19 & 0,2776 & 0,2119 & 19 & 0,1683 & 0,1271 \\
\hline 20 & 0,2706 & 0,2072 & 20 & 0,1686 & 0,1276 \\
\hline
\end{tabular}

Fonte: elaboração dos autores.

Tabela 13. Alíquota atuarialmente justa $\left(\tau_{\mathrm{eq}}\right)$ por gênero. Taxa de crescimento da renda $=2 \%$ a.a. Renda Inicial=3 SM.

\begin{tabular}{ccc|ccc}
\hline & Mulheres & \multicolumn{3}{|c}{ Homens } \\
\hline Idade de Início & \multicolumn{2}{|c|}{ Taxa de Desconto } & Idade de Início & Taxa de Desconto \\
\cline { 2 - 6 } de Contribuição & $3 \%$ & $4 \%$ & de Contribuição & $3 \%$ & $4 \%$ \\
\hline 16 & 0,2244 & 0,1699 & 16 & 0,1406 & 0,1052 \\
\hline 17 & 0,2268 & 0,1722 & 17 & 0,1672 & 0,1255 \\
\hline 18 & 0,2291 & 0,1744 & 18 & 0,1679 & 0,1264 \\
\hline 19 & 0,2313 & 0,1766 & 19 & 0,1683 & 0,1271 \\
\hline 20 & 0,2333 & 0,1787 & 20 & 0,1686 & 0,1276 \\
\hline
\end{tabular}

Fonte: elaboração dos autores. 


\section{Análise de sensibilidade: os impactos de um crescimento da renda mais elevado}

Em todos os cálculos da seção anterior adotou-se uma taxa de crescimento real da renda de 2\%. Embora esta taxa seja baseada em evidências empíricas da literatura (ver, por exemplo, Giambiagi e Afonso 2009), esta escolha (bastante conservadora) traz implícita certo grau de incerteza, dado o grande horizonte temporal associado ao ciclo de vida de um contribuinte da previdência social.

Associado a este fato, podem ser citadas as elevadas taxa de crescimento do PIB verificadas nos últimos anos, com exceção do ano de 2009, em que os efeitos da crise de 2008 ainda se fizeram sentir. Dados do IPEADATA mostram que no período 2000-2009 o PIB real cresceu a uma taxa média anual de 3,33\%. Com base neste fato, e nas perspectivas de crescimento futuro da economia brasileira, nesta seção faz-se uma extensão do modelo apresentado anteriormente. São aqui apresentados os resultados considerando que a renda dos contribuintes cresça, em termos reais, a uma taxa $r$ de $4 \%$ ao ano.

\section{Resultados: taxa de crescimento da renda $=4 \%$ ao ano}

Apresentam-se inicialmente, nas Tabelas 14 e 15 os resultados da taxa de reposição (TR) calculados quando a renda cresce a uma taxa de $4 \%$ ao ano. Como pode ser notado, os resultados reportados na Tabela 14 são sobremaneira inferiores àqueles apresentados na Tabela 10 , em que a renda cresce à taxa de $2 \%$ por ano.

O motivo é taxas de crescimento maiores levam a valores de renda mais elevados. Para os grupos de mulheres mais jovens, isto significa uma redução na necessidade de subsídio implícito, argumento que se aplica aos resultados da Tabela 14. Para os indivíduos com renda mensal igual a 3 SM (Tabela 15, que deve ser comparada com a Tabela 11), significa atingir mais rapidamente o teto das contribuições e benefícios, em que o efeito sobre estes últimos parece ser mais relevante.

Para todos os grupos, atingem-se também mais rapidamente os intervalos em que a alíquota de contribuição é mais elevada. O que se pode concluir é que, embora o benefício também aumente, a taxa com que isto ocorre é inferior à taxa de incremento da renda. 
Tabela 14. Taxa de reposição (TR) por gênero. Taxa de crescimento da renda $=4 \%$ a.a. Renda inicial=1 SM (Valores em reais).

\begin{tabular}{ccc} 
Idade de Início de Contribuição & Mulheres & Homens \\
\hline 16 & 0,349 & 0,327 \\
\hline 17 & 0,361 & 0,401 \\
\hline 18 & 0,373 & 0,416 \\
\hline 19 & 0,386 & 0,431 \\
\hline 20 & 0,399 & 0,447
\end{tabular}

Fonte: elaboração dos autores.

Tabela 15. Taxa de reposição (TR) por gênero. Taxa de crescimento da renda $=4 \%$ a.a. Renda inicial=3 SM (Valores em reais).

\begin{tabular}{ccc}
\hline Idade de Início de Contribuição & Mulheres & Homens \\
\hline 16 & 0,323 & 0,277 \\
\hline 17 & 0,334 & 0,340 \\
\hline 18 & 0,345 & 0,353 \\
\hline 19 & 0,357 & 0,366 \\
\hline 20 & 0,369 & 0,380 \\
\hline
\end{tabular}

Fonte: elaboração dos autores.

As Tabelas 16 e 17 trazem os resultados da alíquota de contribuição atuarialmente justa $\tau_{\text {eq, }}$ dada uma taxa de crescimento da renda de $4 \%$ ao ano. Estes resultados devem ser comparados com aqueles apresentados nas Tabelas 12 e13. Há queda para todas as alíquotas calculadas.

É importante assinalar que a queda é mais expressiva para a faixa de renda mais baixa (1 SM) e para as mulheres, particularmente aquelas que iniciaram sua vida ativa mais cedo.

Ou seja, períodos de maior crescimento econômico, com repercussão na renda devem ser mais benéficos aos grupos mais pobres, às mulheres e aos que iniciaram sua vida ativa mais cedo.

Esta parece ser uma importância evidência empírica de aspectos distributivos no sentido correto, advindos da existência do sistema previdenciário. Assim, podese eventualmente esperar que se um período de crescimento consistente e bastante prolongado da renda se materializar, possa haver reflexo no RGPS, com redução das alíquotas de contribuição. 
Tabela 16. Alíquota atuarialmente justa $\left(\tau_{\text {eq }}\right)$ por gênero. Taxa de crescimento da renda $=4 \%$ a.a. Renda Inicial $=1$ SM.

\begin{tabular}{ccc|ccc}
\hline & Mulheres & & \multicolumn{2}{c}{ Homens } \\
Idade de Início & \multicolumn{2}{c|}{ Taxa de Desconto } & Idade de Início & \multicolumn{2}{c}{ Taxa de Desconto } \\
\cline { 2 - 3 } de Contribuição & $3 \%$ & $4 \%$ & de Contribuição & $3 \%$ & $4 \%$ \\
\hline 16 & 0,2449 & 0,1879 & 16 & 0,1573 & 0,1200 \\
\hline 17 & 0,2475 & 0,1905 & 17 & 0,1871 & 0,1432 \\
\hline 18 & 0,2500 & 0,1930 & 18 & 0,1879 & 0,1442 \\
\hline 19 & 0,2525 & 0,1954 & 19 & 0,1885 & 0,1450 \\
\hline 20 & 0,2547 & 0,1978 & 20 & 0,1889 & 0,1457 \\
\hline
\end{tabular}

Fonte: elaboração dos autores.

Tabela 17. Alíquota atuarialmente justa $\left(\tau_{\text {eq }}\right)$ por gênero. Taxa de crescimento da renda $=4 \%$ a.a. Renda Inicial=3 SM.

\begin{tabular}{ccc|ccc}
\hline & Mulheres & & \multicolumn{2}{c}{ Homens } \\
\hline Idade de Início & \multicolumn{2}{c}{ Taxa de Desconto } & Idade de Início & \multicolumn{2}{c}{ Taxa de Desconto } \\
\cline { 2 - 6 } de Contribuição & $3 \%$ & $4 \%$ & de Contribuição & $3 \%$ & $4 \%$ \\
\hline 16 & 0,2264 & 0,1738 & 16 & 0,1335 & 0,1018 \\
\hline 17 & 0,2289 & 0,1762 & 17 & 0,1588 & 0,1215 \\
\hline 18 & 0,2312 & 0,1785 & 18 & 0,1595 & 0,1223 \\
\hline 19 & 0,2335 & 0,1807 & 19 & 0,1600 & 0,1231 \\
\hline 20 & 0,2356 & 0,1829 & 20 & 0,1603 & 0,1236 \\
\hline
\end{tabular}

Fonte: elaboração dos autores.

\section{Conclusões}

Neste artigo apresentou-se um modelo atuarial simples. Este modelo foi empregado para o cálculo de uma série de variáveis ligadas à aposentadoria por tempo de contribuição do INSS.

Dentre os cálculos efetuados estão os valores presentes de contribuições e de benefícios, valores dos benefícios líquidos, taxas de reposição previdenciária e alíquota de contribuição atuarialmente justa.

Os cálculos foram apresentados para diferentes idades de início de contribuição, taxa de desconto e também separados por gênero. Foi feita também uma análise de sensibilidade, por meio da alteração da taxa de crescimento da renda.

Apesar de simples, o modelo permite a obtenção de uma série de resultados interessantes. O primeiro refere-se às mulheres que começam sua vida ativa com a remuneração de 1 SM. Para estas, é necessário um subsídio implícito por parte do sistema previdenciário, visto que, dadas as regras da ATC, não conseguem um volume de contribuições tal que Ihes garanta o benefício pelo menos igual ao piso previdenciário de $1 \mathrm{SM}$. Este fato é constatado também por meio do valor presente líquido (VPL) positivo que apresentam. 
Os resultados mostram também que as taxas de reposição referentes à ATC são sempre próximas a 0,5 , com exceção das mulheres cuja renda inicial é igual a 1 SM. A principal explicação deve-se ao fato de o fator previdenciário nas idades de aposentadoria analisadas ser bastante inferior à unidade, o que reduz sobremaneira o salário de benefício.

Cabe comentar ainda que os valores encontrados são, em geral, bem mais baixos que aqueles reportados por Forteza e Ourens (2009) para uma série de países da América Latina. No entanto, as taxas de reposição aqui calculadas são, também de forma geral, comparáveis às taxas apresentadas na resenha feita por Ferreira (2007) para um conjunto de dezoito países da OECD.

Os resultados indicam que as alíquotas contributivas atualmente vigentes, de $28 \%$ a $31 \%$, são superiores ao que seria necessário para os benefícios programáveis, como é o caso da aposentadoria por tempo de contribuição, exceto no caso das mulheres que contribuem para o sistema com um salário mínimo a uma taxa de desconto de 3\% a.a.

Esta é a principal conclusão advinda do cálculo das alíquotas atuarialmente justas, apresentado na seção anterior. Também deve ser ressaltado que maiores taxas de crescimento da renda parecem ser mais benéficas às pessoas que iniciaram sua vida laboral mais cedo e cuja remuneração seja mais baixa, e também à mulheres. Este fato pode ser entendido como uma evidência da existência de aspectos distributivos no RGPS.

Com base nos resultados apresentados são feitas a seguir quatro considerações no âmbito das políticas públicas:

a) Parece ser possível afirmar que o sistema previdenciário brasileiro, particularmente o RGPS do INSS tem impactos distributivos importantes. O mais importante desses aspectos distributivos é intrageracional, visto que as alíquotas de contribuição atuarialmente justas sempre são maiores para as mulheres que para os homens. No entanto, para as faixas de renda inicial igual a 1 SM, as taxas de reposição são similares. Este fato deve-se às mulheres não conseguirem alcançar um salário de benefício superior ao piso previdenciário. Este fato é reforçado pelos resultados encontrados quando se adotou a hipótese de crescimento da renda a uma taxa mais elevada;

b) Do ponto de vista atuarial parece ser relevante pensar-se em uma equiparação das regras de aposentadoria por tempo de contribuição entre homens e mulheres, uma vez que foi constatado que parte do benefício de aposentadoria das mulheres está sendo subsidiado pelo restante dos contribuintes à previdência social, particularmente os homens do setor formal. Em contrapartida, as alíquotas de contribuição dos homens revelaram-se superestimadas para um benefício tipicamente previdenciário, como a ATC; 
c) É importante atentar para a influência do fator previdenciário nas taxas de reposição e nas alíquotas necessárias, particularmente quando a aposentadoria ocorre com idades reduzidas, o que é mais provável, dado o diferencial de condições de elegibilidade, para as mulheres. Caso venha a se concretizar alguma reforma paramétrica que contemple o aumento da idade mínima para a aposentadoria por tempo de contribuição, estes impactos podem vir a ser acentuados;

d) Talvez seja necessário colocar na agenda de reformas previdenciárias do Brasil a separação das alíquotas contributivas para os benefícios de risco. Esta mudança tornaria mais transparente o ônus associado aos riscos cobertos pela previdência social. E, desta maneira, poderia ser um ferramenta de decisão importante aos gestores públicos para que adotassem políticas que não onerassem excessiva ou incorretamente nenhum grupo.

\section{Referências}

Afonso LE, Zylberstajn H, Souza AP. Mudanças na previdência social: uma avaliação dos efeitos das reformas paramétricas no RGPS. Economia. 2006, $7(4): 37-69$.

Biggs AG, Brown J R. Springstead, G. Alternative methods of price indexing social security: implications for benefits and system financing. NBER Working Paper 11406, 2005. Disponível na internet em: http://www.nber.org/papers/w11406 [Acesso em 15 jan. 2011].

Delgado GC, Querino AC, Rangel L, Stivali M. Avaliação de resultados da lei do fator previdenciário (1999-2004). Texto para discussão 1161, IPEA, 2006. Disponível na internet em: http://www.ipea.gov.br/pub/td/2006/td_1161.pdf [ Acesso em 25 out. 2010].

Feldstein M. Social security, induced retirement and aggregate capital accumulation. / Polit Econ. 1974, 82(5):905-25.

Ferreira SG. Sistemas previdenciários no mundo: sem "almoço grátis". In: Tafner P, Giambiagi F. (Orgs.) Previdência no Brasil: debates, dilemas e escolhas. Rio de Janeiro: IPEA, 2007.

Forteza A, Ourens G. How much do Latin American pension programs promise to pay back? Social Protection Discussion Paper 0927. Washington, DC: World Bank, 2009.

Fox A. Earnings replacement rates of retired couples: findings from the retirement history study. Social Security Bull. 1979, 42(1): 17-39. 
Giambiagi F, Afonso LE. Cálculo da alíquota de contribuição previdenciária atuarialmente equilibrada: uma aplicação ao caso brasileiro. Rev Bras Econ. 2009, 63(2):153-79.

Giambiagi F, Mendonça JLO, Beltrão KI, Ardeo VL. Diagnóstico da previdência social: o que foi feito e o que falta reformar? Pesq Plan Econ. 2004, 34(3):365-418.

Giambiagi F, Zylberstajn H, Afonso LE, Souza AP, Zylberstajn E. Impacto das reformas paramétricas na previdência social brasileira: simulações alternativas. Pesq Plan Econ. 2007, 37(2): 175-220.

Jordan CW. Life contingencies. 2a ${ }^{\text {a }}$ edi. Chicago: Society of Actuaries, 1967.

Mitchell OS, Phillips JWR. Social security replacement rates for alternative earnings benchmarks. Michigan Retirement Research Center 2006-116, 2006.

Queisser M, Whitehouse E. Neutral or fair? Actuarial concepts and pensionsystem design. OECD Social, Employment and Migration Working Papers 40, 2006.

Ribeiro PD, Fígoli MGB. Análise econômica e social da introdução do fator previdenciário na nova regra de cálculo dos benefícios da previdência social brasileira. In: Fígoli MGB, Queiroz BL. (Orgs.). Estudos sobre previdência social no Brasil: diagnóstico e propostas de reforma: Demografia em Debate, vol. I. Belo Horizonte: ABEP, 2008.

Souza AP, Zylberstajn H, Afonso LE, Flori, PM. Resultados fiscais da reforma de 2003 no sistema de previdência social brasileiro. Pesq Plan Econ. 2006, 36(1):1-38.

Veall MR. Public pensions as optimal social contracts. / Pub/ Econ. 1986, $31(2): 237-51$.

Zorzin PLG. Previdência social e desigualdade racial no Brasil. Dissertação (Mestrado) - Centro de Desenvolvimento e Planejamento Regional (UFMG). Belo Horizonte, 2008. 